\title{
Bilateral total corneal epithelial erosion as a side effect of cytotoxic therapy
}

\author{
A Hirsh, A Alhalel, A Weiss, H Brener, I Avni
}

\begin{abstract}
Bilateral total corneal epithelial erosion and descement folds are reported as toxic side effects of 5-fluorouracil in a patient with end stage carcinoma of the stomach.
\end{abstract}

The antimetabolite 5-fluorouracil (5-FU) is a pyramidine analogue that has shown significant activity against carcinomas of the breast and gastrointestinal and genitourinary tracts. The drug is generally administered by rapid intravenous injection and has a plasma half time of 10 minutes. The most noted side effects of parenteral 5-FU include nausea, vomiting, stomatitis, dermatitis, alopecia, and peripheral neuropathy. ${ }^{1-3}$ Cerebellar ataxia may be seen after three to four weeks due to accumulation of fluorocitrate, which is a metabolic product of 5FU and known as a potent inhibitor of the Krebs cycle in cerebellar tissue. ${ }^{4}$

The main known eye disorders among the toxic side effects of 5-FU are epiphora, hyperaemia, blepharitis, conjunctivitis, and blurred vision. These have usually resolved rapidly after the drug is discontinued. ${ }^{46} \mathrm{~A}$ direct correlation between the amount of lacrimation and the concentration of the drug in the tears has been found. ${ }^{7}$ The systemic use of the drug can cause tear duct fibrosis. ${ }^{8}$ Cicatricial ectropion has also been described in patients with excessive lacrimation receiving 5-FU. ${ }^{9}$ Oculomotor disturbances, especially weakness of convergence or divergence due to regional 5-FU neurotoxicity affecting the brain stem, have been described. ${ }^{10}$ In the following report we present a rare case of bilateral total corneal epithelial erosion and descement folds in a patient treated with intravenous 5-FU as a palliative for carcinoma of the stomach.

\section{Case report}

A 67-year-old man was referred to the Eye Department from the Oncology Clinic of our hospital because of sudden decreased visual acuity. Seven days after admission he was treated with a chemotherapeutic course of $170 \mathrm{mg} 5-\mathrm{FU}$ daily for carcinoma of the stomach. This treatment was discontinued on the fourth day because of the appearance of nausea, vomiting, and stomatitis, together with blurred vision on the second day.

On examination the visual acuity was $6 / 60$ in both eyes, and the intraocular pressure was normal. No signs of epithora or conjunctival irritation were present. Both corneas showed total epithelial erosion and descement folds. The anterior chambers were deep, with no reaction. The retina and the optic nerve were normal.

The patient was treated with synthomycin ointment $5 \%$ and patches, and was examined the following day, with identical findings. Unfortunately he died a day later from cardiorespiratory arrest.

Since the metabolism of the cornea is mainly from the aqueous humour and the tear film, ${ }^{11}$ a drug affecting the corneal epithelium and stroma after systemic administration is expected to achieve toxic levels in both fluids. The appearance of conjunctivitis following systemic 5-FU therapy has been reported before, and it is related to the toxic side effects on all mucous membranes. In our case the corneal involvement appeared two days after a severe stomatitis.

In conclusion, corneal epithelial erosion and descement folds may represent a potential toxic side effect of 5-FU, and may appear as a part of its clinical manifestations. 1 Ansfield FJ, Schnoeder JM, Cursen AF. Five years clinical
experience with 5-FU: $7 A M A 1962 ; 181: 295-9$.

2 Mortel CG. Chemotherapy of gastrointestinal carcinoma. Clin Gastroenterol 1976; 5: 777-93.

3 Chabner BA, Myer CE. Clinical pharmacology of cancer chemotherapy. In: DeVita VT, Hellman S, Rosenberg SA eds. Cancer. Principles and practice of oncology. Philadelphia: Lippincott, 1989: 349-95.

4 Griffin DJ, Garnick MB. Eye toxicity of cancer chemotherapy: a review of the literature. Cancer 1981; 48: 1539-49.

5 Fraunfelder FT. Interim report: national registry of possible drug-induced ocular side effects. Ophthalmology 1980; 87: $87-90$.

6 Fraunfelder FT, Meyer SM. Ocular toxicity of antineoplastic agents. Ophthalmology 1983; 90: 1-3.

7 Hamersley J, Luce JK, Florentz TF, Burkholder MM, Pepper JJ. Excessive lacrimation from fluorouracil treatment. FAMA 1973; 225: 747-8.

8 Haidak DJ, Hurwitz BS, Yeung KY. Tear duct fibrosis (dacryostenosis) due to 5-fluorouracil. Am Intern Med 1978; 88: 657 .

9 Straus DJ, Mansolf FA, Ellerby RA, McCracken JD. Cicatricial ectropion secondary to 5-fluorouracil therapy. Med Pediatr Oncol 1977; 3: 9-15.

10 Brixenman WW, Nicholls JVV, Warwick OH. Oculomotor disturbances associated with 5-FU chemotherapy. Am f Ophthalmol 1977; 88: 789-93.

11 Woltman SR, Hart WM. In: Moses RA, Hart MH, eds. Adler's physiology of the eye: clinical application. St Louis: Mosby, 1987: 45-7. 